\title{
5. Regional orientation, strategic development and knowledge infrastructure
}

\subsection{IMPORTANCE OF REGIONAL ENGAGEMENT FOR INNOVATION}

Research active universities are potentially crucial actors in 'knowledge-based' regional innovation systems, but some have a much greater impact than others. This is shaped by two sets of factors: on the one hand, the managerial, regulatory, and infrastructural frameworks in which universities interact with their local environment defines the RII potential and chances of success. On the other hand, strategic partnerships with regional authorities and other actors in the innovation system allows this potential to be realised. While some universities may take a leading role, even helping to orchestrate the whole innovation system (e.g. Rissola et al., 2017), their regional impact also relies on the performance of other actors and the collective implementation of a common strategy.

Within universities, strong leadership and an encouraging environment supportive of entrepreneurial and innovative processes is essential for their RII performance (Sánchez-Barrioluengo and Benneworth, 2019). Leadership must be responsive for an organisation to be dynamic and successful. Flexibility, adaptability, and adequate resources are indispensable for successfully navigating such dynamic environments; to survive and thrive during unpredictable and complex times (Johannessen and Skaalsvik, 2014). University leadership and governance can incentivise locally oriented entrepreneurial and outreach behaviour, driven by a university-wide shared vision and culture that incorporates RII prioritisation.

University leaders who have dealt primarily with their internal organisational environment are increasingly required to manage relationships with a wide range of private and public sector stakeholders. More than in the past, they must be able to demonstrate the value they add to society in order to qualify for their share of increasingly scarce public resources. In doing so, they need to give the entire organisation a common purpose, challenging all their 
staff to ask themselves not just what they are good at, but what they are good for (Goddard et al., 2016). This is increasingly framed not only in terms of economic growth but also in terms of a wider contribution that helps achieve the United Nations Sustainable Development Goals (Nhamo and Mjimba, 2020). In 2019 the Times Higher Education Impact Rankings including metrics related to the SDGs for the first time.

University leadership needs to create appealing RII stories and an accompanying culture of regional innovation. Although RII, in one way or another, may be mentioned in a university's vision statements or strategic plans, the ambitions with regards to a university's societal stewardship, custodians of regional heritage or culture, or other engagements with local communities are often not explicitly defined or described. The regional orientation, in terms of generating RIIs, should not ignore or underscore the relevance of social innovations and a large variety of societal impacts. Examples include citizenship, policy debate, environmental awareness, cultural enlightenment, and general well-being of the population. Although not directly or necessarily of immediate economic significance, these impacts may have huge longer-term positive effects on the effectiveness and sustainability of regional innovation systems. Even more importantly, these impacts are a defining characteristic and integral product of many universities, which runs through all dimensions of their societal mission.

Senior university managers are now expected to cooperate with local and regional policymakers, to help them deal with complex policy and practical challenges on issues such as strategic development or supportive knowledge infrastructure. The development of regional partnerships with governmental and private sector actors can help to align university and regional strategies to better match supply and demand for knowledge and skills, especially in the context of 'Smart Specialisation' (Edwards et al., 2020), a policy concept that has gained momentum among the European Union's regions (see Box 5.1).

\section{BOX 5.1 SMART SPECIALISATION STRATEGY}

In 2010 the European Commission called on national and regional governments to develop a 'Smart Specialisation' strategy for research and innovation to encourage all European regions to discover and develop their competitive advantage (European Commission, 2010). The approach was operationalised principally through the European Regional Development Fund, which requires Member States to have a smart specialisation strategy at national and/or regional level in order to make R\&I investments. Smart specialisation policies are designed to empower those institutional actors that are capable of realising potentials with the aim of generating distinctive 
competitive advantages in a regional economy (Foray and Goenaga, 2013; Goddard et al., 2013).

The resulting policy processes are meant to select and prioritise those areas where a cluster of activities could develop, usually those which are already strong or show promise for a region and which can benefit from (more) R\&D and innovation. Smart specialisation policies advocate regional partnerships to foster 'entrepreneurial discovery processes' (Foray, 2014). Effective regional smart specialisation requires effective partnerships, sustained coherent objectives and policies, and open and inclusive systems with the participation of all regional stakeholders. When properly aligned, regional innovation policies may reinforce each other at the regional level (Fitjar et al., 2019).

Regional governments are also becoming increasingly aware of the importance of building stronger partnerships with universities, particularly in terms of the skills and human capital integration within innovation policies (Edwards et al., 2020). Europe's smart specialisation agenda has challenged Member States to introduce new forms of governance that facilitate collaborative leadership. In this new context, universities in Europe are facing important challenges, mainly associated with demands to become more entrepreneurial, with stronger leadership to shape innovation policy in cooperation with other local and regional R\&I actors.

One of the features of smart specialisation is that regions are challenged to create a shared vision among the different R\&I actors. Universities can play the role of a 'neutral knowledge broker', reconciling different interests and perspectives, helping to lead regional participatory processes (European Commission, 2020). This can be particularly important in regions with low levels of trust and without a culture of cooperation and civic engagement. Similarly, the smart specialisation approach relies on a process of entrepreneurial discovery where bottom-up search processes provide the information required for policymakers to set innovation priorities. Universities can help bring together the entrepreneurial and innovation communities to explore the strengths of a region, while operating as an intermediary with the regional government. Such a role for universities is even more important in less developed regions with low levels of 'institutional thickness' (Vallance et al., 2018; Zukauskaite et al., 2017).

Applying our analytical model and the RII analytical framework, as displayed in Figure 2.1 (section 2.1), this chapter touches on two categories in that framework: the 'Needs, problems and issues' with the local or regional environment and its relationship to 'Goals and motivation' on the university side. Focusing our attention on the university perspective, sections 5.2 and 
5.3 present an illustrative overview of how various universities engage with local, regional, and national authorities to (co-)develop and implement their RII-related objectives, strategies and programmes. Section 5.4 explores the interactions between the international and regional levels, adding another level to the analytical framework that is displayed in Figure 3.1 (section 3.1) and how research-intensive universities are uniquely positioned to harness global knowledge for the benefit of the place in which they are located. The final 'Conclusion' section summarises the main findings and draws some general conclusions.

\subsection{RII DELIVERY SPACE: COLLABORATION IN REGIONAL SPECIALISATION STRATEGIES}

Universities are in the position to help create institutional environments where education, science, business, and government meet and interact. By broadening and strengthening local or regional collaborations and connections, universities are better positioned to address socio-economic challenges. Such partnerships are also seen as desirable to shape a region's innovation strategy. Challenges and obstacles to regional innovation systems which universities can help to overcome include brain drain, low levels of lifelong learning and entrepreneurial skills, and few intermediaries to facilitate cooperation. The role and position of the university can determine the shape and nature of the entire regional innovation system, especially if those universities become innovation system integrators (Rissola et al., 2017). Most universities in our sample maintain active relationships with the local and regional authorities as well as other stakeholders in the region. Many universities are an institutional partner in strategic agreements for regional development, or a participant in regional coordination bodies. The RII self-appraisal reports include a variety of organisational arrangements, which not only illustrates the wide range of possibilities but also how much the interplay between universities and their local governing bodies may depend on local circumstances and opportunities.

Two out of three of the young innovative ${ }^{1}$ universities in our sample; Aalto University, Aalborg University and the University of Stavanger were established relatively recently with the clear mission to help bring about either the building or rebuilding of their regional innovation ecosystems creating new business opportunities for their collaborating partners or attracting new industrial development to the region. Their strong dynamic management actively

1 Self-declared 'innovative universities' as members of European Consortium of Innovative Universities (ECIU). 
engages with regional governmental actors and other stakeholders in their regional ecosystem to contribute to the definition of a shared vision.

A recent case study of Aalto University (Rissola et al., 2017) analysed the way it helps orchestrate its regional innovation system, by interacting with regional actors while generating new business opportunities and new businesses, for example by bringing researchers from university and industry together on its campus around strategic new areas of development. Norway's University of Stavanger, another entrepreneurial university, actively supports three regional cluster initiatives within the Norwegian government's ARENA programme designed to support immature, but high-potential clusters. In collaboration with the Stavanger municipality the university also participates in the EU Smart Cities and Communities Lighthouse project 'Triangulum' for transforming Stavanger into a smart city/region. Another initiative is the Strategic Business Plan developed by Greater Stavanger Economic Development. The priority areas for development outlined in this plan tie into the current strengths and future development priorities of the university. Aalborg University (see Appendix C) was established with the explicit aim of raising the innovative and economic potential of North Denmark, a less developed region in the Danish context. It has a long-standing cooperation with the local authority and regional growth centre to promote strategic cooperation in common regional innovation challenges.

Turning to some examples of technical universities in our sample one observes they seek to align with their region's specialisation objectives - and often help shape them. The University of Strathclyde's Principal is Chair of the Glasgow Economic Leadership Board, which brings together business and civic leaders and has played a key role in developing the Glasgow City economic strategy. This Board includes leaders of the ten key economic sectors in the city today; students and researchers of the university engage strongly in five of these sectors. The University of Strathclyde is also an anchor organisation in the development of the National Manufacturing Institute for Scotland (NMIS) as part of Glasgow's Manufacturing Innovation District. The NMIS is a strategic collaboration between the Scottish Government and the university to enhance the competitiveness of Scottish industry through adoption of cutting-edge research and innovation, and improving skills provision.

The regional government of Turin developed a new strategic plan, to define priorities, in terms of regional technological specialisations giving the university system a key role. In line with the regional strategic plan, the Technical University of Turin (see Appendix D) implemented programmes aimed at supporting the ongoing transformation towards a more diversified economic system, integrating Information and Communication Technologies (ICT) to the traditional manufacturing competences of the region, while favouring the creation of new industries. It created 11 new inter-departmental research 
centres focusing on the key enabling technologies with the objective to tackle the current regional needs of nurturing and diversifying the economic system towards emerging technologies. The Technical University of Catalunya is one of the most active participants in the RIS3CAT communities, a programme put in place by the Catalan government to ensure the continuous engagement of stakeholders in the selected smart specialisation priority areas. The university aligns its efforts to create ecosystems that foster research, innovation, and entrepreneurship with the RIS3CAT communities' organisational structures.

Considering smaller universities with a regional focus, the University of Ruse strongly intensified its work with business and regional authorities through a number of initiatives: Employers Days, developing an Information Portal for Business Partners, and joint projects with business under the Operational programmes of the Bulgarian government. The university plays an important role in the configuring of the regional systems and policies. Many of the key figures in regional public institutions are alumni of the University of Ruse. Furthermore, representatives of the university participate in all specialised committees, established at local and regional level, and make a significant contribution to solving local and regional problems in Bulgaria and the Bulgarian-Romanian cross-border region. Rovira i Virgili University in Catalunya (see Appendix F for details) has built up a network of six public research centres, four technology centres and various business associations, all of which have close connections to the regional priorities. This network facilitates the interaction between the university, the research and technological centres, and the manufacturing sector.

The large comprehensive universities in our sample also actively interact with their regional governments in the development of regional or municipal development strategies. Academics at the University of Warsaw were involved in creating the city's 'Development Strategy 2030', the main strategic document for local authorities. Together with municipal officials these experts in regional development, geography, economics, and sociology co-created a broad-scale inclusive process leading to recommendations for the city's future development (see Appendix E for more information on the University of Warsaw). Leiden University in the Netherlands is now co-located in two neighbouring municipalities: Leiden and The Hague. The university aims to reinforce its presence in The Hague by participating in The Hague Security Delta, and strengthening its collaboration with the University of the Arts. Moreover, Leiden University is a partner in national and international administrative, political and legal institutions in The Hague to further enhance The Hague's specialisation profile: a city of international law, peace and security, a centre of Dutch public administration, and increasingly as the city of international governance. Leiden University, Delft University of Technology, and Erasmus University Rotterdam, have created a strategic alliance in the South 
Holland region of the Netherlands with inter-university centres and joint science and scientific-medical programmes. Italy's University of Bologna played a key role in the creation and development of the Emilia-Romagna High Technology Network. Focusing on the specific characteristics of the regional ecosystem, the university directly participates in several regional coordination bodies. The university is one of the founders and shareholders of the Regional Coordination Agency for Technological Innovation, ASTER, which steers all the activities of the ER High Tech Network, and acts as the Scientific Advisor for the Strategic Plan of the large Bologna Metropolitan Area. The Catholic University of Leuven (see Appendix B) regularly consults with its local stakeholders, such as the Leuven-based Interuniversity Microelectronics Center (Imec) and the city council members of its hometown. Since 2016 these interactions have been further consolidated leading to the establishment of the 'Leuven Mindgate' initiative to enhance the city's regional branding. The university has built strong ties with several other cities in the Belgium province of Flanders, allowing the university to extend its network of science parks and incubators. There are also very intense collaborations with the province of Flemish Brabant in order to promote the entire region as a knowledge hub to attract foreign companies, via an initiative called 'Flanders Smart Hub'. At the Flemish government level, the university collaborates with agencies like Flanders Innovation \& Entrepreneurship, Science Foundation Flanders, the Department of Economy, Science and Innovation of the Flemish Government, and Flanders Investment and Trade.

\section{BOX 5.2 UNIVERSITIES AND MONITORING OF SMART SPECIALISATION STRATEGIES}

Innovation strategies help to create 'learning regions' (Morgan, 1997), whereby a territorial knowledge base is co-created among innovation actors and codified by regional authorities. However, this is no easy task and public authorities often lack the technical skills and capabilities to collect and analyse such data. They would be wise to look at regions where public authorities and universities have worked together in this task. Furthermore, monitoring is an essential part of smart specialisation strategies (Gianelle et al., 2016), which makes it more important for all regions to develop this territorial knowledge base. An example of such cooperation is the Northern Netherlands Innovation Monitor, which was set up in the University of Groningen by the Northern Netherlands Alliance, the regional body responsible for smart specialisation. It includes an annual survey of SMEs to understand their characteristics, behaviour and potential discovery of new innovation opportunities. Following the principle of reciprocity, the mon- 
itor provides each participating SME with a benchmark report, as well as the chance to join an expert panel or policy review workshop, allowing local firms to influence the development of smart specialisation priorities. Another example is from the University of Vaasa in Finland, which, in cooperation with the Regional Council of Ostrobothnia, has designed a tool called the Connectivity Model to measure the connections and interactions between local actors. Based on a survey, focus groups and gap analysis the tool has helped Ostrobothnia to better understand its regional innovation system and which areas of innovation to prioritise in its smart specialisation strategy.

While there is clear potential, few of the case studies show how the universities' social sciences research capacities contribute to generating knowledge on the regional innovation system and smart specialisation. There are some examples, such as the development of a sub-regional innovation scoreboard at Rovira i Virgili University, the contribution of social scientists of the University of Warsaw to its city's development strategy, or the partnership between The Hague municipality and Leiden University to explore the possibilities of incorporating urban issues in the research carried out by the university research teams. However, we can find inspiration from other universities, such as those involved in the JRC project on Higher Education for Smart Specialisation. Box 5.2 shows how universities have been key partners for regions in monitoring their smart specialisation strategies.

\subsection{RII DELIVERY SPACE: INTER-REGIONAL AND INTERNATIONAL COOPERATION}

Research-active universities usually have significant international networks through joint projects and publications, which are necessary to remain at the forefront of an academic field and to access funding. Internationalisation has also increased within higher education, with growing levels of mobility among students and staff (the Erasmus programme has accelerated this trend within Europe). On the one hand this is a challenge to the university's RII because academics are called upon to educate 'citizens of the world' which are less likely to enter the local labour market. Research is targeted towards peers and when policy relevant usually national or supranational authorities rather than the regional level. These factors are built into the career incentives of individual academics as well as objectives for departments and faculties. However, the case studies also show that universities can act as a link between the global and local levels, absorbing international knowledge and sharing this with other 
regional stakeholders. Institutional funding needs to recognise and value this role more.

A first example of how universities can help internationalise the regional ecosystem is provided by Aalto University. At the time of its establishment in 2010, substantial effort was given to increasing the new university's international position and in a short period of time it has expanded its global reach. For example, the UN Technology Innovation Lab network is located on the campus, as is a business innovation incubator of the European Space Agency. This international profile helps to attract talent and business, improving the whole regional innovation system. Kaunas University of Technology provides an example of the importance of international ties in the Baltics. Its local region spans several countries. The university's national innovation and entrepreneurship centre through its business incubator start-up space leads inter-regional projects for entrepreneurship promotion. These projects are focused on strengthening links between Lithuanian, Polish and Latvian neighbouring districts. In February 2012, the Kaunas University of Technology and Aalto University's Centre for Entrepreneurship signed a memorandum, which was the basis for establishment of the university's Innovations and Entrepreneurship Centre.

Smaller regionally oriented universities tend to have more limited possibilities to engage internationally, except through the opportunities provided by the EU Framework Programmes. However, some can benefit from their specific geographical location. For example, the University of Ruse has built a reputation as a knowledge hub within the Danube macro region. It has participated in key projects of the European strategy for the Danube as well as many cross-border projects with Romanian partners, funded by the InterReg programme. This in turn has helped North Central Bulgaria and the city of Ruse develop local and regional innovation strategies, although the impact is limited by a national approach to smart specialisation.

Larger comprehensive universities often play at the European or even global scientific stage. They can help embed their local region in international networks. Leuven University has partnered with other regional actors in European initiatives, notably the EIT Knowledge and Innovation Communities, in which the university acts as an innovation hub for two (Raw materials and Food) and is an active partner in two more (Health and Energy). An example at the project level is EnergyVille, funded both by EIT Innoenergy and the ESIF. Leuven University is actively involved in cross-border collaborations, such as ELA-T, a network linking Leuven region to universities in Eindhoven (Netherlands) and Aachen (Germany). Appendix B provides more detail on the Catholic University of Leuven. The University of Bologna has developed a structured long-term approach at the regional level in aligning local policies with the EU Framework programmes. This strong link with a supra-national 
programming context has made it easier to reconcile the short-term quest of an advanced industrial system mainly based on SMEs, with the participation in long-term innovation challenges.

\subsection{CONCLUSION}

This chapter argued that universities can make a major contribution to regional development strategies, acting as 'anchor organisations' that promote knowledge as a driver of economic development. Some universities even take an orchestrating role in conjunction with other actors in their regional innovation system. Dynamic management is a central factor in this, although it is also shaped by the regulatory environment and other structural factors outside the university's control.

Turning to our RII analytical framework in Part I, the chapter illustrated how universities engage with regional governance structures and align their activities with specific regional priorities. Assessing a university's performance in these RII delivery spaces also requires an assessment of how its internal resources and incentives react to those of the regional innovation system as a whole and the way this feeds into it through its goals and motivation.

The multi-level nature of innovation impact is shown through the examples of universities cooperating with international partners, not just in terms of research but through links with other actors in the different regional innovation systems. Such interactions are increasingly supported by EU funding such as through the EIT Knowledge and Innovation Communities, a component of its R\&I framework programmes that aims to build systems rather than just fund individual projects. These systems bring together the education, research, and enterprise development activities of universities, which are addressed more closely through examples in the following chapters. 